\title{
Cuidados e o impacto da aparência estética na percepção social de um grupo de mulheres idosas
}

\author{
Care and the impact of aesthetic appearance on the social perception on a group of elderly women
}

Márcia de Mello ${ }^{1}$ (D)

Helenice de Moura Scortegagna' $\mathbb{D}$ Nadir Antonio Pichler' (ID)

\section{Resumo}

Objetivo: descrever e explorar os cuidados e o impacto da aparência estética na percepção social de um grupo de mulheres idosas. Método: Estudo exploratório e descritivo, de cunho qualitativo, realizado por meio de um questionário sociodemográfico e uma entrevista semiestruturada, com 11 mulheres idosas, participantes de um grupo de convivência. O que emergiu das falas compôs o material para análise temática de conteúdo. Resultados: A extração em unidades temáticas permitiu a elaboração de duas categorias que se entrelaçam e complementam: Sentir-se bem é a palavra-chave e Cuidados com a aparência. Conclusão: nas percepções das participantes, cuidados e aparência possuem relação com a estética corporal, facial e capilar, geradores de autoestima, satisfação, felicidade, liberdade, bemestar psíquico e bem-estar social e foram concebidos como meios eficazes de integração familiar, social e profissional, motivando-as para enfrentar as vicissitudes existenciais. Essa constatação está em consonância com a expressão da liberdade, do diálogo, da autodeterminação e autoconhecimento, do reconhecimento e da inserção social.

\section{Abstract}

Objectives: Describe and explore the care and impact of the aesthetic appearance of a group of elderly women. Method: Exploratory and descriptive study, of a qualitative nature, carried out through a sociodemographic questionnaire and a semi-structured interview, with 11 elderly women, participants in a social group. What emerged from the speeches composed the material for thematic content analysis. Results: The extraction in thematic units allowed the elaboration of two categories that intertwine and complement each other: Feeling good is the key word and Care for appearance. Conclusion: in the participants' perceptions, care and appearance is related to body, facial and capillary

Palavras-chaves: Saúde da Mulher. Estética. Liberdade. Mulher Idosa.
Keywords: Womem's Health. Aesthetic. Freedom. Elderly Women. 
aesthetics, generating self-esteem, satisfaction, happiness, freedom, psychological wellbeing and social well-being and was conceived as an effective means of family, social, and professional integration, motivating them to face the existential vicissitudes. This finding is in line with the expression of freedom, dialogue, self-determination and selfknowledge, recognition and social insertion.

\section{INTRODUÇÃO}

Nas últimas décadas, em nível mundial, observase uma mudança no estilo de vida das pessoas. Existe uma crítica aos valores tradicionais do patriarcado, das religiões e das morais e há uma busca por valores que aspiram a autonomia do sujeito, independentemente de sua condição econômica, social e profissional e grau de instrução. Essa revolução no mundo da vida também tem como protagonistas mulheres idosas, que estão reconstruindo seus valores existenciais, sobretudo diante das mudanças nas novas configurações familiares, papéis sociais e sexuais, mercado de trabalho, etc., principalmente pela influência dos grupos de convivências. Esses grupos propiciam espaços para o fortalecimento de suas subjetividades, canalizando e expressando um novo jeito de ser e agir, como o cuidado de $\mathrm{si}^{1}$. Essa atitude de inserção social é capaz de "deixar fruir a vida para a invenção de modos singulares de existência"2. Assim, os grupos promovem atividades de lazer, estudo, viagens, intercâmbios, voluntariado, espírito de acolhida e equipe, espiritualidade, bem como o bem-estar físico e psíquico, enaltecendo a arte de viver bem e feliz com autonomia, confiança, cidadania, autoestima, dignidade, ou seja, uma estética da existência ${ }^{3,4}$.

Michel Foucault (1926-1984) concebe a estética ou arte da existência e o cuidado de si como "autoperfeição e autoafirmação do sujeito", por meio de práticas racionais e voluntárias e um conjunto de regras de condutas atribuídas a si pelo sujeito, com a finalidade de transformar-se num ser singular, portador de "certos valores estéticos e que corresponda a certos critérios de estilo" . Ainda, está centrada no modo de ser próprio e no cuidado de si do indivíduo inserido numa sociedade, como cidadão livre, com oportunidade de progredir moralmente e intelectualmente, capaz de conquistar sua liberdade pessoal, social e cívica, ${ }^{7,8}$.
A partir da análise histórica e criteriosa das éticas gregas e romanas, como estoicismo, cinismo e epicurismo, Foucault extraiu um cabedal filosófico voltado para o cuidado de si e, consequentemente, para uma estética da existência ou cuidado de si. Mesmo sendo um modo de existência autônoma voltada para cidadãos privilegiados do mundo antigo $^{2}$, do qual Foucault recebeu duras críticas, principalmente de Charles Taylor, Pierre Hadot e Richard Rorty, a estética da existência pode ser estendida a todas as pessoas da contemporaneidade, das sociedades liberais, por meio de suas morais laicas, imanentes e históricas. Essas morais enaltecem a liberdade, a fraternidade, a igualdade, a autonomia, a felicidade, o belo, a beleza física e estética, enfim, a subjetividade. "São modos de subjetivação, tal como os entende Foucault, [e] trata-se de uma produção de sujeitos éticos"2.

A estética da existência é uma forma de subjetivação, uma obra de arte centrada na ascese, na purificação, na espiritualidade, no domínio de si que transcende os códigos de condutas apresentados pela sociedade. Não é um modo de ser heterônomo, compulsório, metafísico e estritamente extrínseco, moldado por valores transcendentes, rígidos, dogmáticos, mas intrínseco, deliberado, passível de escolha e de determinação de si mesmo, como sujeito racional para inserir-se de forma consciente no mundo, como uma prática de si, "concebida como um combate permanente. Não se trata, simplesmente, de formar para o futuro um homem de valor. É preciso dar ao indivíduo as armas e a coragem que lhe permitirá lutar a vida inteira". Ou seja, a pessoa tem a possibilidade de se atribuir regras existenciais diferentes das estandardizadas, tradicionais e convencionais, muitas vezes mercadológicas, consumistas e alienadas, esculpindo, moldando e cuidando de si mesma. É cuidar de si mesmo para depois voltar e se inserir na sociedade como cidadão moderno. Não é um modo de viver egoísta e 
narcisista, mas partilhado por "indivíduos de idade, estatuto e atividade sociais diferentes" .

A estética da existência está ancorada no cuidado de si. Do grego epimeleia heautou, esse cuidado estrutura-se na dimensão ética do sujeito, do éthos, ou seja, na arte de viver bem e feliz, na prática da liberdade, da autonomia e no cultivo dos valores da alma, do eu, por meio de um estilo de vida com atitude de autogoverno e autarquia. É uma maneira de ser, pensar e agir no mundo e no cuidado com os outros ${ }^{10-13}$.

E essa maneira de ser e existir tem despertado o cuidado com a estética corporal de mulheres idosas. Sentimentos de liberdade, segurança, satisfação com a vida e felicidade são condições almejadas pelo ser humano, bem como a possibilidade de escolher e manter uma aparência estética desejável ${ }^{2,4,6,7}$.

Considerando que o processo do envelhecimento humano é gerador de alterações anátomo-fisiológicas, psicológicas e sociais, e, consequentemente, de cuidados com a estética corporal, imagem e autoestima, há necessidade de ampliar os estudos acerca da temática, identificando percepções de satisfação com a aparência física, a vida, a aceitação e adaptação com o corpo e a idade, o contato social, familiar e social ${ }^{2,8}$.

O objetivo do artigo foi descrever e explorar os cuidados e o impacto da aparência estética na percepção social de um grupo de mulheres idosas.

\section{MÉTODO}

Trata-se de um estudo de abordagem qualitativa, do tipo exploratório e descritivo, por meio de aplicação de um questionário sociodemográfico e uma entrevista semiestruturada, com 11 mulheres idosas, participantes de grupo de convivência da Coordenadoria de Atenção ao Idoso (DATI), constituído por mulheres, realizado de agosto a outubro de 2018, vinculado ao projeto integrado de pesquisa Envelhecimento, Educação e Saúde, desenvolvido num Programa stricto sensu em Envelhecimento Humano, em um município do Sul do Brasil.
A seleção dos participantes foi por conveniência e a definição do tamanho da amostra determinada pela saturação dos dados.

A partir da autorização da direção do grupo e de contato prévio, foi realizado o agendamento dos encontros, com data e hora, de acordo com a preferência das participantes, num ambiente reservado no espaço onde ocorrem os encontros do grupo. Os critérios de inclusão foram ter idade igual ou superior a 60 anos, frequentar o grupo de convivência e ter disponibilidade para participar da pesquisa e de exclusão, não estar presente no momento da coleta de dados. As entrevistas foram realizadas individualmente e tiveram duração de 30 minutos cada, com as seguintes questões norteadoras: O que é estética ou beleza para você? Quais são os cuidados habituais com a sua aparência? A opinião dos outros sobre a sua aparência interfere na sua participação no grupo de convivência? O cuidado com sua aparência tem influência nos aspectos sociais e emocionais da sua vida?

As informações foram analisadas qualitativamente, utilizando-se a análise de conteúdo de Bardin ${ }^{14}$, por meio da leitura flutuante em pré-análise, exploração do conteúdo e interpretação, "procurando descobrir o que se esconde sob os documentos selecionados, na busca da compreensão do fenômeno investigado". Depois, foi sintetizado, por inferência, em unidades de significância, considerando a exaustividade, a representatividade, a pertinência e a homogeneidade e elaboração de categorias temáticas, a partir de critérios semânticos baseados no objetivo do estudo.

Para preservar a identidade das participantes nos excertos de seus relatos foi usado I (idosa) e o número arábico que indica a sequência da entrevista. O projeto foi aprovado pelo Comitê de Ética em Pesquisa da Universidade, com o parecer n. 2.628.706.

\section{RESULTADOS E DISCUSSÃO}

As participantes têm entre 60 e 83 anos de idade, com média de idade de 72 anos. A maioria é aposentada, com renda pessoal entre um a três salários mínimos. Seis têm até três filhos, quatro têm mais de três e uma não tem. Dez idosas residem 
com familiares e uma vive sozinha. Cinco possuem de 5 a 8 anos de estudo e seis, com mais de 8 anos. Seis são viúvas, quatro casadas e uma é separada. A partir do que emergiu das falas das participantes, foi possível construir duas categorias: Sentir-se bem é a palavra-chave e Cuidados com a aparência.

\section{Sentir-se bem é a palavra-chave}

As participantes mencionaram que a estética corporal proporcionou autoestima e confiança, fazendo-as sentir-se bem, com estímulo para buscar a felicidade do interior ao exterior, estando a beleza física como meio, caminho, e não como o objetivo maior, de acordo com as falas:

"Me sinto confiante, alegre, até para vir na aula me sinto melhor, elogiada" (I 3).

"É importante para toda a mulher. Tem dias que a gente se sente bem, se sente feliz, bonita (I 9).

"A aparência é de dentro para fora" (I 10).

"A gente fica mais feliz, se sente melhor" (I 11).

Na visão de Goldenberg ${ }^{15}$, a velhice revela-se, cada vez mais nas últimas décadas, como um tempo para cuidar de si mesmo, da saúde, das amizades e dos netos, para rir, dançar, viajar, estudar, namorar, não sendo necessário "responder, desesperadamente, às expectativas dos outros". Com o envelhecimento, há uma mudança de propósito, de foco, onde a pessoa idosa passa a cuidar mais de si mesma, criando espaços para o desenvolvimento da autonomia e da liberdade, tese corroborada pelas falas acima. No mesmo sentido, para Foucault ${ }^{10}$, quando uma pessoa consegue desenvolver um estilo próprio, investindo e produzindo no cuidado de si, torna-se artesão de sua beleza, fazendo, do seu modo de ser, uma obra de arte. Assim, as éticas do mundo grego e romano tinham como princípios que o cidadão não se submetesse ao poder das autoridades, nem fosse escravo, estrangeiro, muito menos, deixasse se dominar as paixões, que deveriam ser racionalizadas por meio de exercícios, como meditação, contemplação, exame de consciência e troca de correspondências, e buscar a felicidade como um bem maior, supremo, cuidando da vida como um todo ${ }^{6,9-11}$. Para alcançar o equilíbrio entre o corpo, a alma, as relações com o outro (alteridade) e a divindade, era necessário ocupar-se consigo mesmo pela prática da ascese (askésis), pela modificação e enaltecimento de sua subjetividade, em relação ao corpo, pensamento e conduta, para transformar-se em sujeito moral.

As percepções das mulheres idosas em relação a aparência física e estética estão associadas aos cuidados diários da beleza e da vaidade e esse modo de ser influência substancialmente no cuidado de si, relacionamento e comportamento. Conceberam a estética relacionada ao cotidiano, capaz de contribuir para a adaptação e integração familiar, social e profissional, melhorando a confiança e a autoestima. Porém, uma pessoa não concorda com a aparência ser usada para discriminação étnica e condição social:

"Já notei que as pessoas fazem diferença entre tratar bem quem tem uma aparência melhor ou não, o que eu acho triste” (I 9).

"A gente fica mais feliz, se sente melhor. Muitas vezes é até bem tratada. [...]. Não tenho vergonha de estar com outra pessoa mais arrumada que eu" (I 11).

"Tudo depende da tua autoestima. Se você estiver bem arrumada, às vezes você vai num lugar, mas a roupa não está de acordo com o local, depende se tu acertou ou não” (I 5).

"Quando as pessoas me encontram e dizem que eu estou bem, eu fico contente" (I 8).

"Se não estou me sentido bem com a minha aparência, fico me sentindo meio de lado" (I 1).

Para Cerqueira ${ }^{16}$, quando a velhice passa a ser uma etapa natural e bem-vinda, a aparência, apesar de ser importante e promotora de bem-estar físico e psíquico, não necessita obedecer e seguir ao padrão de beleza exigido pela sociedade. Neste sentido, um estudo realizado com mulheres idosas, frequentadoras de um grupo de convivência vinculado a uma Unidade Básica de Saúde, no Sul do Brasil, demonstrou que, com o avançar da idade e as marcas naturais do envelhecimento, as idosas 
não se sentem intimidadas, porque vestem-se e agem agradavelmente na intenção de se sentirem satisfeitas com sua imagem corporal ${ }^{17}$.

As práticas de si, como o cuidado de si e a estética da existência, estão vinculadas as regras do meio social. Se o sujeito rompe bruscamente e constrói um jeito de ser independente dessas normas, sentese deslocado do seu mundo exterior. Por isso, cabe a pessoa buscar um equilíbrio nas relações sociais, mantendo sua autonomia e adaptando-se aquilo que é conveniente numa sociedade "associado aos saberes e às relações de poder ${ }^{10}$. Foucault ressalta o valor da singularidade e o grau de independência conquistado pelo indivíduo na esfera das relações privadas aos quais o sujeito pertencia no mundo grego e romano, como a família, as atividades domésticas e os “interesses patrimoniais". Essa estética da existência possibilitava intensificar as relações consigo mesmo, como objeto de conhecimento e campo de "ação para transformar-se, corrigir-se, purificar-se, e promover a própria salvação" ${ }^{10}$. Ora, o tempo dispensado pelas participantes deste estudo no cuidado de si, por meio da aparência, realça essa singularidade.

Ainda, em relação a influência da aparência na vida diária das entrevistadas, relataram que dispensam um tempo para cuidar e manter a beleza corporal, como ir ao cabeleireiro, a manicure em vestir-se bem, porque há uma preocupação com a vaidade para sentir-se elegante, sensual e bonita. Assim, há uma percepção estética no processo do envelhecimento voltado ao cuidado de si atuando de forma positiva, com autoestima, para conviver e enfrentar as vicissitudes existenciais:

"Eu sempre tiro tempo para me cuidar, ir ao cabeleireiro, a manicure, porque a mulher precisa disso" (I 1).

"Influencia positivamente” (I 7).

"Acho importante esses cuidados, porque você se sente bem" (I 2).

"Se você olha e vê que está bem, o seu dia é legal" (I 5).

"Se você se olha e se gosta, o dia é diferente. A autoestima é tudo para a pessoa" (I 6).
"Quando a gente não tá legal, a gente não se sente bonita" (I 11).

De acordo com Goldenberg ${ }^{15}$, no Brasil, o culto ao corpo jovem e esbelto é considerado "verdadeiro capital", como um bem a ser gerenciado, preservado e cuidado. É um meio para conquistar a liberdade e a felicidade e manter uma identidade social. Ainda, na pergunta o que você mais inveja em outras mulheres, "elas responderam: corpo, beleza, juventude, magreza e sensualidade. O corpo invejado por elas é jovem, magro e sensual". Goldenberg enaltece o tempo que as mulheres brasileiras utilizam para cuidar de si e uma emancipação das "antigas servidões sexuais, procriadoras e indumentárias”, porém, sempre acompanhado de ansiedade, devido as coerções estéticas imperativas oriundas da sociedade.

\section{Cuidados com a aparência como estética da existência}

Os cuidados que as participantes relataram estão relacionados com a aparência física e a estética corporal, com uma associação entre saúde e beleza. Essa relação, inicialmente, está ligada ao bem-estar físico, como manter o peso, alimentação adequada e equilibrada, exercícios físicos por meio de caminhadas, aulas de ginástica e pilates, mas com repercussão no bem-estar psíquico, na autoestima, confiança e satisfação e no bem-estar social. Eis algumas falas:

"Mas quando alguém fala como você está magra ou gorda eu não gosto, me sinto mal” (I 8).

"É bem válido me cuidar, ter cuidados com a aparência. Fui sempre de me cuidar, na alimentação [...], principalmente depois dos 60 anos. Não gosto de engordar, exijo estar bem” (I 5).

"Quando engordo um pouquinho já começo a cortar o carboidrato [...]. Para pra mim, eu me sentir bem já é importante, mais que a aparência (I 1).

"Não é pela aparência. Eu sou assim. Quem gostar de mim tem de gostar como sou” (I 4).

Foucault $^{10}$, parafraseando Sócrates, considerado pela tradição grega e romana como o mestre do 
cuidado de si e da estética da existência, destaca que o cuidado com o corpo e a aparência física, bem como a riqueza, os bens exteriores e o dinheiro, é algo salutar e condição essencial para satisfazer as necessidades biológicas e materiais. Porém, a partir dessas condições e cuidados, busca-se alcançar e desenvolver os valores da alma, "do ocupar-se consigo mesmo", em "forma de uma atitude, de uma maneira de se comportar". Essa forma de viver requer reflexão, aperfeiçoamento e prática e possui repercussão nas relações intersubjetivas, promovendo o bem-estar social. Se, de um lado, havia a preocupação com o cuidado de si, de outro, havia conexões locais e familiares fortes "de relações de clientela e de amizade $^{10}$.

Em sentido semelhante, Fin et al. ${ }^{18}$, asseguram que a beleza na velhice é apreendida como um processo que exige o cuidado de si e de suas relações sociais. Constitui-se num olhar atencioso sobre o corpo e a alma, que segue regras, condutas e princípios, tais como fazer exercícios, manter bom humor, dançar, se agitar, procurar o médico quando não se sente bem e, até mesmo, ocupar-se com causas sociais.

A maioria das mulheres idosas manifestou que, dentre os cuidados habituais com aparência, estão o corte de cabelo, seguido de coloração e manicure. Esse autocuidado com a estética traz uma sensação de jovialidade à mulher, bem como a valorização de sua beleza física e o cuidado estético. Essa dedicação e olhar sobre si mesmas estão ancoradas na estética capilar, facial e corporal, elaborados a partir de gostos e experiências cotidianas, como revelam as falas abaixo:

\footnotetext{
“Se o cabelo já não está se ajeitando, então, eu vou lá marco o corte, faço as luzes, procuro mudar, troco o corte e a roupa não fica bem eu descarto (I 2).

"Me preocupo com a aparência, pois posso encontrar alguém e passar por desleixada. Só quando vou num evento, demoro mais" (I 8).

"Procuro sempre estar em ordem, cabelo, unha, me pintar um pouquinho, me vestir, cuidar do todo" (I 3).
}

Segundo Goldenberg ${ }^{19}$, na atualidade e de forma cada vez mais acentuada, é possível viver a velhice com beleza, autonomia, felicidade e liberdade, porque "envelhecer é verbo, ação, continuidade. [...] Fomos diferentes no passado e seremos diferentes no futuro". Um estudo realizado com dez idosas demonstrou que há uma preocupação com a estética corporal e ser saudável, com cuidados com a pele, cabelos, unhas, sempre acompanhado de atividade física, em vista da liberdade e da autonomia e como reconhecimento social ${ }^{20}$.

Em relação a opinião das pessoas da mesma idade sobre a sua aparência estética, as idosas relataram que se sentem, de um lado, incomodadas e desafiadas, principalmente quando se olham no espelho, e, de outo, motivadas, com autoconfiança e autoestima. Para elas, o cuidado estético está ligado aos pensamentos, sentimentos e percepções, oriundas de suas vivências, experiências e influências socioculturais do meio ao qual estão inseridas:

\footnotetext{
"Sentir que minha aparência está agradando me faz bem" (I 10).

“É tudo, é minha autoestima” (I 6).

"É importante! Eu gosto de sempre estar meio combinando" (I 7).

\begin{abstract}
"Algum lugar mais importante que a gente vai eu olho [referindo-se as outras idosas], mas não que eu me sinta inferior. É só uma avaliação. Eu costumo me auto avaliar no espelho [...]. Principalmente antes de sair" (I 4).
\end{abstract}

"Eu tenho que olhar no espelho e tenho que me gostar. Não vou me vestir para ti nem para ninguém. Eu me visto pra mim" (I 2).

"Eu não me importo muito com a aparência. Mas eu noto que num dia de uma festa quando me arrumo melhor, eu me sinto melhor" (I 11).

Foucault ${ }^{10}$ enfatiza a necessidade da pessoa examinar a si mesma, à própria consciência, como um juiz de si diante dos atos e costumes realizados e daquilo que os outros dizem e pensam. Essa estética da existência não visa perscrutar sobre a culpabilidade e gerar remorso sobre as argúcias de si, mas estimular a pessoa a progredir moralmente, intelectualmente e alcançar uma "conduta sábia", à semelhança das percepções do cuidado e da aparência estética das 
mulheres idosas. Assim, o processo do pensamento sobre si mesmo, também chamado por Foucault de cultura de si, tem a função de efetuar uma filtragem "permanente das representações: examiná-las, controlá-las e triá-las"10. Ainda, partindo da beleza exterior, as participantes demonstraram preocupação em enaltecer a beleza interior, aprimorando suas identidades, autonomias e papéis sociais.

O estudo de Marinho e Reis ${ }^{21}$, com 10 idosas longevas, com idade de 80 anos ou mais, mostrou e sintetizou que as palavras mais utilizadas pelas participantes foram "sinto, jovem, maravilhosa, oitenta, estou linda, cabelo, arrumo, bonita, creme, batom e cuidar". Dentre os achados ainda, as mulheres idosas consideraram-se longevas alegres, envelhecendo de forma saudável, com boa saúde, disposição, "autonomia, independência, conservando o espírito jovem". Foucault ${ }^{10}$ denomina essa estética da existência como uma "conversão de si", uma prática de si em direção ao cultivo da identidade e da felicidade, resultados de uma longa jornada de conhecimento, autoconhecimento e cuidado de si.

Uma pesquisa desenvolvida por Elfving-Hwang ${ }^{22}$, na Coreia do Sul, com vinte mulheres idosas, da área metropolitana de Seul, com o objetivo de explorar a aparência estética, demonstrou que o cuidado com o corpo é uma preocupação diária, capaz de gerar autoestima, autonomia e engajamento social. Outro estudo, de Cameron et al. ${ }^{23}$, de revisão sistemática, com o objetivo de identificar as perspectivas de mulheres sobre envelhecimento, saúde e imagem corporal, destacou que há uma preocupação constante com o corpo e o processo de envelhecer, como a perda da beleza, da jovialidade e da identidade. A maioria das mulheres relataram insatisfação com a imagem corporal e essa percepção gera sofrimento emocional e isolamento social.

\section{REFERÊNCIAS}

1. Moura MMD, Veras RP. Acompanhamento do envelhecimento humano em centro de convivência. Physis. 2017;27(1):19-39.

2. Tótora S. Velhice: uma estética da existencias. São Paulo: EDUC; 2016.
Enfim, o processo de envelhecer também é um período da vida para conquistar e enaltecer a liberdade, a segurança, o charme, o reconhecimento ${ }^{24}$, o respeito, a independência, o prazer, o "autoconhecimento e muito mais" ${ }^{\prime 13}$. Foucault ${ }^{10}$ concebe esse aprimoramento e polidez do sujeito de estética da existência, que é a busca pela liberdade, autoestima e autoafirmação relatadas pelas participantes deste estudo. Diante do exposto, sugere-se aprimorar a metodologia com discussões em grupo focal e estabelecer conexões a partir do cuidado de si e estética corporal com o bem-estar subjetivo e a qualidade de vida.

\section{CONCLUSÃO}

As participantes relataram que os cuidados dispensados com a estética corporal, facial e capilar proporcionaram autoestima, confiança, satisfação, felicidade, liberdade, bem-estar psíquico, bemestar social. Ainda, uma boa aparência corporal foi concebida como um meio, um caminho eficaz de integração familiar, social e profissional e capaz de gerar motivação para enfrentar as vicissitudes existenciais, porque está intrinsecamente ligada a pensamentos, sentimentos e percepções, advindos de suas vivências, experiências e influências socioculturais.

De acordo com as falas das mulheres idosas, as expressões e percepções que emergiram enalteceram a busca do cuidado de si, com ênfase no cuidado com a aparência física como expressão de liberdade, de diálogo, de autodeterminação e autoconhecimento, de reconhecimento e de inserção social. Todas essas expressões de cuidado com a aparência física demonstraram um diálogo profícuo das mulheres idosas consigo e com o outro.

Editado por: Ana Carolina Lima Cavaletti
3. Araújo LSA, Moreira ACA, Freitas CSL, Silva MAM, Val DR. Idosos e grupos de convivência: motivos para a não adesão. SANARE. 2017;16(1):58-67.

4. Annes LNB, Mendonça HGS, Lima FM, Lima MAS, Aquino JM. Perfil sociodemográfico e de saúde de idosas que participam de grupos de terceira idade em Recife, Pernambuco. Rev Cuid. 2017;8(1):1499-1508. 
5. Costa JF. O sujeito em Foucault: estética da existência ou experimento moral? Tempo Soc. 1995;7(1-2):121-38.

6. Foucault M. Estética: literatura e pintura, música e cinema. $4^{a}$ ed. Motta MB, tradutor. São Paulo: Forense Universitária; 2015. (Col. Ditos \& Escritos 3).

7. Zanetti FL. A Estética da existência e a diferença no encontro da arte com a educação. Educ Real. 2017:42(4):1439-58.

8. Bazza AB. A constituição da subjetividade no discurso do idoso sobre si. Ling (Dis)curso. 2016;16(3):449-64.

9. Foucault M. A Hermenêutica do sujeito. $4^{\mathrm{a}} \mathrm{ed}$. Fonseca MA, Muchail ST, trad. São Paulo: Martins Fontes; 2010.

10. Foucault M. História da sexualidade: O cuidado de si. $9^{\mathrm{a}}$ ed. Albuquerque MTC, tradutor. Rio de Janeiro: Graal; 2009. Vol. 3.

11. Mcnay L. Foucault and feminism: power, gender and the self. Cambridge: Polity Press; 2007.

12. Smith D. Foucault on ethics and subjectivity: 'Care of the Self' and 'Aesthetics of Existence'. Foucault Stud. 2015;(19):135-50.

13. Gaus N. Philosophy and politics in higher education. Qual Res J. 2019;19(3):294-306.

14. Bardin L. Análise de Conteúdo. $4^{\mathrm{a}}$ ed. Pinheiro LA, trad. São Paulo: Edições 70; 2016.

15. Goldenberg M. A invenção de uma bela velhice: em busca de uma vida mais livre e feliz. Rev Bras Geriatr Gerontol .2018;21(5):529-30.
16. Cerqueira BM. Míticas do envelhecimento: em busca de uma vida saudável. Ciênc Soc Unisinos. 2017;53(1):148-57.

17. Mincoff RCL, Silva PA, Lourenço MP, Nogueira IS, Baldissera VDA. Dialogues on the body image of the elderly: community empowerment strategy promoting health. Rev Rene. 2018;19:1-8.

18. Fin TC, Portella MR, Scortegagna SA. Estética e expectativas sociais: o posicionamento da mulher idosa sobre os recursos estéticos. Rev Kairós. 2015;18(4):133-49.

19. Goldenberg M. A bela velhice. São Paulo: Editora Record; 2014.

20. Kowalski PJ, Shemes C, Saraiva AIJ, Magalhães LMl. Mulheres idosas: percepções sobre beleza e envelhecimento. Temas Mujeres. 2017;76-97.

21. Marinho MS, Reis LA. Velhice e aparência: a percepção da identidade de idosas longevas. Rev Kairós. 2016:19(1):145-60.

22. Elfving-Hwang J. Old, down and out?: appearance, body work and positive ageing among elderly South Korean women. J Aging Stud. 2016;38:6-15.

23. Cameron E, Ward P, Mandville-Anstey SA, Coombs A. The female aging body: a systematic review of female perspectives on aging, health, and body image. J Women Aging. 2018;31(1):1-15.

24. Santana K, Dias ARL, Ferraz AF, Rodrigues RAS, Viana MV, Bocalini DS, et al. Equations for estimating the body aesthetic of young women. J Phys Educ Sport. 2019;19(2):1222-9. 